\title{
Surface Topography in Three-Dimensional Laser Machining of Structural Alumina
}

\author{
Hitesh D. Vora ${ }^{1 *}$ and Narendra B. Dahotre ${ }^{1,2}$
}

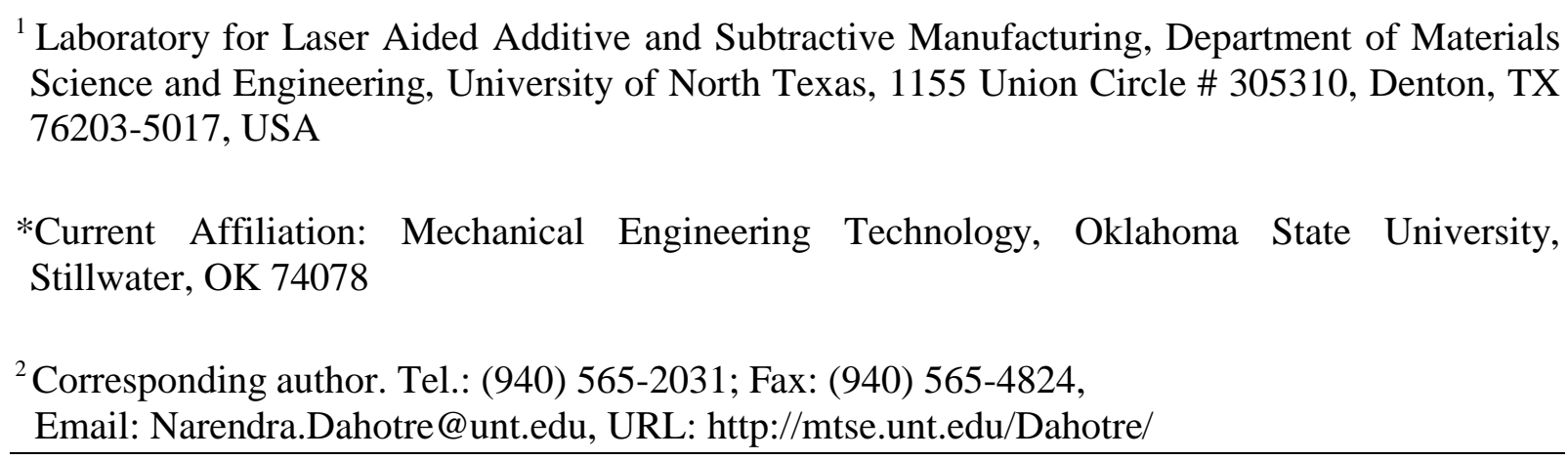

\begin{abstract}
An integrated experimental and computational approach was adopted to study the influence of moving laser beam (with lateral and transverse overlap) on the generation of corresponding surface finish//profile/roughness during three-dimensional laser machining of structural alumina. A multiphysics-multistep computational model was developed to understand the influence of various physical phenomena such as recoil pressure, Marangoni convection, surface tension, and cooling rates over the surface morphology of alumina and eventually establish the relationship between the surface finish and process parameters of laser machining. Both experimental and computational results evidently revealed that the selection of appropriate laser machining conditions can machine the structural ceramics with higher material removal rates $(60 \pm 2.70$ $\left.\mathrm{mm}^{3} / \mathrm{min}\right)$ for initial rough cuts as well as produced higher surface finish $(39.9 \pm 2.29 \mu \mathrm{m})$ for final finishing. The results of the computational model are also validated by experimental observations with reasonably close agreement $( \pm 6 \%)$.
\end{abstract}

\section{Keywords}

Nd:YAG laser; Laser machining; Moving Laser Beam; Structural ceramics; Alumina $\left(\mathrm{Al}_{2} \mathrm{O}_{3}\right)$; Multiphysics computational model; Surface roughness 


\section{$1 \quad$ Introduction}

Structural ceramics (alumina, magnesia, zirconia, silicon carbide, and silicon nitride), can be considered as an effective solution in a variety of industries including automobile, aerospace, medical, printing, textile, and electronic because of their ability to resist deformation at elevated temperature, excellent wear and thermal shock resistance, chemical inertness, superior electrical properties, and lower density [1-5]. On contrary, hard and brittle nature ( 1200-2200 Knoop hardness and $\sim 3-5 \mathrm{MPa}-\mathrm{m}^{1 / 2}$ fracture toughness) of structural ceramics causes serious limitations towards machining into desirable components using conventional machining techniques such as grinding, cutting, polishing, and their derivative processes [5-11]. In addition, these processes are inherently associated with several disadvantages such as undesirable tool wear, inadequate dimensional accuracy, mechanical or thermal damage to workpieces, lower material removal rates, and surface and subsurface micro-cracks [5, 12-16]. Among these conventional machining techniques, grinding is the most popular method to fabricate structural ceramics with good surface finish and higher dimensional accuracy regardless of their longer machining time and higher operating costs $[6-8,17]$. Hence, for various industrial applications a more efficient and economical machining technique is sought.

In this regard, laser based unconventional machining (non-contact laser beam) can be considered as an effective solution to manufacture complex components from the structural ceramics $[1,2,5,17-29]$. The main characteristics of laser machining, which are practically not possible to attain by conventional techniques, are (i) laser beam is highly directional, coherent, and monochromatic (same wavelength), (ii) laser beam delivers a high energy/power in a small 
concentrated area $\left(\sim 0.1 \mathrm{~mm}^{3}\right)$, (iii) generates higher temperatures $(>5000 \mathrm{~K})$ in a very short

laser-material interaction time $(<1 \mathrm{~ms})$, (iv) higher heating and cooling rates $\left(\sim 10^{4} \mathrm{~K} / \mathrm{s}\right)$ due to absorption of high energy laser beam and self-quenching by bulk material, respectively [17-21].

To improve the quality of laser machining, the considerable amount of experimental and numerical/computational works $[1,2,5,15,21-23,30-46]$ were carried out by employing various types of lasers $\left(\mathrm{CO}_{2}\right.$, excimer, and $\mathrm{Nd}$ :YAG) and their operating modes (continuous wave $(\mathrm{CW})$ or pulse mode $(\mathrm{PM})$ ). Especially, for structural ceramics, the PM lasers (pulse width in millisecond range) are more suitable since the lasers concentrate their output energy into series of shorter time high-power $\left(\sim 10^{7} \mathrm{~J} / \mathrm{m}^{2}\right)$ pulses at regular intervals (1 to $\left.100 \mathrm{~Hz}\right)[1,2]$. As a result, significant volume of material is removed at higher material removal rates predominantly by evaporation and partly by melt ejection and dissociation $[1,2]$. However, to achieve higher material removal rate along with the desired surface finish is still a challenging task. In the past, many researchers $[1,2,5,30,31]$ used the experimental and computational approaches to investigate the mechanisms of material removal during laser machining of various structural ceramics $[1,2,9,35,47]$. Although, the main focus of their works was to increase the material removal rates by selecting optimal laser processing parameters, they have completely disregarded the issues related to surface finish. Hence, the undesirable surface finish produced during PM laser machining is still one of the critical issues to be resolved. 
Pulse mode (PM) laser machining can be categorized for one-, two-, or three-dimensional machining (Fig. 1a) to replicate a generic drilling, cutting, and milling (and/or turning) processes, respectively. Although, this classification is just for simplicity, the applications of laser machining are not kept limited to these processes only. In the past, the present authors have already employed an integrated experimental and computational methodology for PM one- and two-dimensional laser machining of structural alumina to investigate the influence of stationary (single [48] or multiple laser pulses [49]) and moving (multiple laser pulses with lateral overlap [50]) laser beam and its effects on evolving surface topography/physical texture/roughness (Fig. 1a). The detailed discussion of laser-material interaction and physical phenomena involved during one- dimensional (stationary laser beam with single [48] or multiple laser pulses [49]) and two-dimensional laser machining (moving laser beam, multiple laser pulses with lateral distance/overlap or center-to-center distance between two laser pulses [50]) and their combined influence on the process of generating surface topography can be found in the authors' previous publications [48-50]. Based on the results of these works, the surface roughness was found to increase with an increase in average laser energy density [48], pulse rate $(10,20,30,40$, and 50 $\mathrm{Hz}$ [ [49], and lateral distance $(\mathrm{dist}=0.6,0.5,0.4,0.3,0.2,0.1 \mathrm{~mm})$ or laser beam overlap $(0,17$, 33, 50, 67, and 83\%) [50]. It was also observed that the increase in crater depth and pile-up height of the machined material around the machined cavity was mainly due to the evaporation induced material lost and recoil pressure-induced fluid flow, respectively.

In an extension of these works and to complete the final category of three-dimensional (3D) laser machining, the present article presents the study on the effect of PM moving laser beam (multiple laser pulses) on the surface topography (finish/roughness) during threedimensional laser machining to mimic/replicate a generic three-dimensional milling process (Fig. 
1a). Particularly, the 3D laser machining is specifically intended to process large area or volume and complex geometries. However, due to the smaller beam diameter $(\sim 0.6 \mathrm{~mm})$, the laser machining of large area or volume is carried out by successive laser racks with the combination of lateral overlap distance (center-to-center distance between two consecutive laser pulses, $\mathrm{D}_{\mathrm{L}}$ ) and transverse overlap distance (transverse distance between two laser tracks, $\mathrm{D}_{\mathrm{T}}$ ) with various scanning configurations (long run, sort run, cross run, spiral run, etc.) (Fig. 1a and 1b).

In light of this, the present article investigated the influence of PM moving laser beam (multiple laser pulses) with combination of both lateral overlap distance $\left(\mathrm{D}_{\mathrm{L}}\right)$ and transverse overlap distance $\left(D_{T}\right)$ and its corresponding lateral overlap $\left(\mathrm{O}_{L}=\frac{\mathrm{D}-\mathrm{D}_{\mathrm{L}}}{\mathrm{D}} \times 100\right)$ and transverse overlap $\left(\mathrm{O}_{T}=\frac{\mathrm{D}-\mathrm{D}_{\mathrm{T}}}{\mathrm{D}} \times 100\right)$, in $\%$ respectively, on the surface topography (physical texture/roughness) during 3D laser machining (Fig. 1b) via an integrated experimental and computational approach. This integrated approach can overcome the difficulties associated with the in-situ measurements of thermo-physical properties (temperature, cooling rates, surface roughness, etc.) during laser machining because heating/ melting/ vaporization occurs in a small confined zone for very short time duration. In this way, this approach can provide more insight into understanding the laser-material interactions during subsequent laser tracks and their consequent effects on evolving surface roughness/ topography/ profile/ physical texture. Hence in this work, unlike authors' previous two-dimensional laser machining computational model [50], an advanced computational model was designed and developed to incorporate the combine effect of both lateral and transverse overlaps (Fig. 1b) with incorporation of temporal and spatial 
heat built up during multiple laser tracks by using the multiphysics finite-element modeling approach followed by its validation with the experimental observations.

\section{$2 \quad$ Multistep Computational Model}

As explained earlier, 3D laser machining can be carried out with various scanning configuration. However for simplicity, in the present case, the PM 3D laser machining, the laser beam is moving continuously along the principle longitudinal axis (X-axis) with predefined scanning speed (Vin) and pulse rate or pulses per second (f) to complete each laser track ( $1^{\text {st }}$ laser track A, laser beam is $\mathrm{ON}$ in forward direction) (Fig. 1). The laser beam overlap or lateral overlap distance $\left(D_{L}=V i n / f\right)$ is the center-to-center distance between two consecutive laser pulses, which is estimated based on the selected scanning speed (Vin) and pulse rate or pulses per second (f). Once the laser beam completes the laser track, the laser beam is turned OFF and the focusing head or workpiece is programed to index along Z-axis by the preset transverse overlap

distance $\left(\mathrm{D}_{T}\right)$ followed by the consecutive laser track $\left(2^{\text {nd }}\right.$ laser track- $\mathrm{B}$, laser beam is $\mathrm{ON}$ in forward direction) (Fig. 1). Similarly, this cycle continuously runs for 'n' number of laser tracks along the surface profile to machine the large surface area and therefore resultant surface topography is evolved (Fig. 1).

Based on the selected transverse overlap value, the interaction of these consecutive laser tracks (e.g. $1^{\text {st }}$ laser track- A and $2^{\text {nd }}$ laser track- B, or successive laser tracks) dramatically influence the resultant surface topography (Fig. 1b). In this regard, the selection of laser machining parameters and their effect on overlapping region caused by lateral overlap distance $\left(\mathrm{D}_{\mathrm{L}}\right)$ and transverse overlap distance $\left(\mathrm{D}_{\mathrm{T}}\right)$ and its corresponding lateral overlap $\left(\mathrm{O}_{\mathrm{L}}\right)$ and transverse overlap $\left(\mathrm{O}_{\mathrm{T}}\right)$, in \% respectively, are very crucial and they play a significant role in 
generating the resultant surface roughness. Therefore, in 3D laser machining, both lateral overlap $\left(D_{L}\right)$ and transverse overlap $\left(\mathrm{D}_{\mathrm{T}}\right)$ can be appropriately varied by selecting appropriate laser parameters (scanning speed and pulse rate) to achieve the desired surface topography.

In view of this, a computational model was designed and developed on the basis of a multiphysics approach on commercially available $\mathrm{COMSOL}^{\mathrm{TM}}$ finite-element platform to precisely mimic the moving PM 3D laser machining process for structural alumina by incorporating both lateral $\left(\mathrm{O}_{\mathrm{L}}\right)$ and transverse $\left(\mathrm{O}_{\mathrm{T}}\right)$ overlaps (in \%). To achieve higher modeling accuracy, the present multiphysics (heat transfer and computational fluid dynamics) computational model incorporated temperature-dependent material properties of structural alumina available in the open literature, the phase change effects due to temperature along with body force (gravitational force with Boussinesq approximation) and surface forces (shear and normal stresses). The shear stresses (tangential component) took into account the temperature dependent surface tension and viscosity whereas the effect of recoil pressure due to vaporized substrate material as function of temperature on normal stresses was considered. The other modeling assumptions are: (i) laser beam profile is in Gaussian distribution (TEM 00 mode), (ii) material is isotropic and opaque, (iii) evaporated/ablated material is transparent and does not interfere with the incident laser beam, and (iv) multiple reflections of laser radiation within the crater are neglected. This approach facilitated evaluation of the temperature field, cooling rates, and velocity of molten material that tend to strongly influence the generation of surface topography under the application of various laser machining conditions.

The present computation model uses the multi-step modeling methodology, outlined in Fig. 2, to predict the evolving surface topography under the 3D laser machining conditions that 
are basically carried out by the application of multiple laser pulses and moving laser beam with both lateral $\left(\mathrm{O}_{\mathrm{L}}\right)$ and transverse $\left(\mathrm{O}_{\mathrm{T}}\right)$ overlaps (in \%). The flow diagram (Fig. 2) shows the systematic multi-step laser machining process progressing from $1 \mathrm{D}$ and $2 \mathrm{D}$ in the previous works to $3 \mathrm{D}$ laser machining presented in the present article. It provides the outline of the process loop and corresponding physical phenomena associated with the progressive approach toward 3D machining.

The selected key governing equations and important boundary conditions for heat flux [51], natural convection cooling and radiation [51], volume force [48-50], recoil pressure [30, 52], Marangoni convection [53], surface tension [54] are summarized in Table 1. The level-set method [55] was specifically used to track the boundaries between solid, liquid and vapor phases to facilitate in estimating the volume loss due to evaporation. The present computational model used the temperature dependent materials properties [56-58] to accurately simulate phase change phenomena during 3D laser machining of structural alumina. However, it is worth mentioning that although typically the emissivity $(\mathcal{E})$ varies significantly with temperature, in the present case a constant value of 0.7 was considered [56] due to the paucity of availability of the temperature dependent emissivity of alumina in the open literature. Furthermore, laser based machining is a complex process involving transition of material through several phases (melting and vaporization) in extremely short duration (micro to milli-seconds in the present work) of the process. Along with phase changes, the laser based machining process also involves additional physical phenomena such as evolution of machined cavity within the substrate and generation of material plume/plasma on the substrate surface. The occurrence of multiple physical phenomena in such short duration makes it, if not impossible, very difficult either to conduct in-situ experimental measurements or design a computational model for obtaining temperature 
dependent emissivity values. This is further complicated with the high temperatures associated with such physical changes in alumina. More details about material properties of structural alumina can be found elsewhere [48-50] and are not presented here to avoid duplication. Unlike earlier work by the same authors on $1 \mathrm{D}$ and 2D laser machining [48-50], the present computational model was uniquely designed and developed to incorporate the combined effect of both lateral and transverse overlaps (Figs. 1 and 2) along with the effect of temporal and spatial heat buildup during multi-track 3D laser machining using the multiphysics finite-element modeling approach followed by its validation with the experimental observations. The lasermachining parameters used for model and experiments are enumerated in Table 2. In the present work, the six combinations of lateral and transverse overlap distances $\left(\mathrm{D}_{\mathrm{L}}-\mathrm{D}_{\mathrm{T}}: 0.6 \mathrm{~mm}-0.6 \mathrm{~mm}\right.$, $0.5-0.5,0.4-0.4,0.3-0.3,0.2-0.2$, and $0.1-0.1$ all in $\mathrm{mm}$ ) were used to machine the structural alumina with laser beam diameter (D) of $0.6 \mathrm{~mm}$. The selection of lateral and transverse overlap distances in turn provides a systematic variation in lateral and transverse overlaps $\left(\mathrm{O}_{\mathrm{L}}-\mathrm{O}_{\mathrm{T}}\right.$ : $0-0$, $17-17,33-33,50-50,67-67$, and $83-83$ all in \%) that facilitate the investigation of its effect on surface topography.

It is pointed out here that the governing Eq. (1) is a function of temperature (T) (Table 1). The evolution of temperature within the laser beam material interaction region depends on laser beam pulse energy $\left(E_{p}\right)$, pulse width $\left(P_{w}\right)$, pulse rate or pulses per second $(f)$, and laser beam scanning speed (Vin). In light of this, the computational model developed in the present work inherently associated with the moving laser beam. As the computational model was developed with a quasi-stationary laser beam approach in which the development (evolution) of temperature and associated effects were considered with a finite laser residence time (or pulse width) that in turn is dictated by the laser scanning speed. This effect is analogous to the process in which one 
would be riding the beam and experiencing/watching the effects in the beam-material interaction region through a bird's eye view. In such situation in spite of the moving beam, the rider tends to experience the illusion of stationary laser-material interaction zone throughout the processing period which in classical sense defined as the quasi-stationary state. Thus in the present work, the 3D laser machining was performed by using moving laser beam. Further, as shown by the multistep modeling approach (Figure \# 2), the model was built by applying one pulse at a time (one-dimensional laser machining) followed by consideration of subsequent laser pulses with lateral overlap distance $\left(D_{L}=\right.$ Vin/f) at both preset beam pulse rate (f) and beam scanning speed (Vin) to complete one laser track (2D laser machining) and finally this 2D laser machining model was repeated with a preset transverse overlap distance $\left(\mathrm{D}_{\mathrm{T}}\right)$ to describe $3 \mathrm{D}$ laser machining.

\section{Experimental Methods}

\subsection{Sample Preparation and Laser Machining}

In the present efforts, alumina plate $\left(90 \times 65 \times 6 \mathrm{~mm}^{3}, 99.6 \mathrm{wt} . \%\right)$ was obtained from Advalue Technology Inc., Tucson, AZ. Laser machining of alumina ceramics was carried out using JK 701 Lumonics pulse mode Nd:YAG (1.064 $\mu \mathrm{m}$ wavelength) laser system. This laser system is equipped with Flashcut CNC controller and in the present efforts; it was programmed to mill $20 \times 20 \mathrm{~mm}^{2}$ cavity with total six laser processing conditions. The laser machining parameters used for PM 3D laser machining are enumerated in Table 2. The PM 3D laser machining was carried out by constant energy per pulse (1J), pulse width $(0.5 \mathrm{~ms})$, and scanning speed $(10 \mathrm{~mm} / \mathrm{s})$, while pulse rate $(\mathrm{f}=17,20,25,34,50,100$ pulses $)$ were varied to achieve the lateral overlap distance $\left(\mathrm{D}_{\mathrm{L}}=\mathrm{Vin} / \mathrm{f}\right)$ of $0.6,0.5,0.4,0.3,0.2,0.1(\mathrm{~mm})$, respectively and its 
corresponding lateral overlap of $0,17,33,50,67$, and $83(\%)$, respectively (Table 2). Similarly, the transverse overlap distances $\left(\mathrm{D}_{\mathrm{T}}\right)$ of $0.6,0.5,0.4,0.3,0.2,0.1(\mathrm{~mm})$ and its corresponding lateral overlap of $0,17,33,50,67$, and $83(\%)$, respectively were used during PM 3D laser machining (Table 2). Therefore, all other laser parameters being same, based on the selected lateral and transverse overlap distances $\left(\mathrm{D}_{\mathrm{L}}-\mathrm{D}_{\mathrm{T}}\right.$ : 0.6-0.6, 0.5-0.5, 0.4-0.4, 0.3-0.3, 0.2-0.2, and 0.1-0.1 all in mm) and its resultant lateral and transverse overlap $\left(\mathrm{O}_{\mathrm{L}}-\mathrm{O}_{\mathrm{T}}: 0-0,17-17,33-33,50-\right.$ $50,67-67$, and 83-83 all in \%), correspondingly total of six effective laser energy densities $\left(\mathrm{E}_{\text {eff }}=\right.$ $6.02,7.08,8.85,12.0,17.7,35.4 \times 10^{7} \mathrm{~J} / \mathrm{m}^{2}$ ) were employed to machine the structural alumina. The beam diameter at the focus on sample surface was $0.6 \mathrm{~mm}$. This is the smallest beam diameter that can be configured with the existing laser system and the focusing optics. In light of this, as clearly stated in in Section 3.1 under Experimental Methods and Table 2 on laser parameters and graphically presented in Figure 1, both the maximum lateral $\left(D_{L}\right)$ and transverse $\left(\mathrm{D}_{\mathrm{T}}\right)$ distance $\left(0 \%\right.$ lateral $\left(\mathrm{O}_{\mathrm{L}}\right)$ and transverse $\left(\mathrm{O}_{\mathrm{T}}\right)$ overlap) that can be maintained between the subsequent laser pulses and laser tracks without leaving any area (volume) unprocessed by laser was $0.6 \mathrm{~mm}$. Any overlap distance larger than $0.6 \mathrm{~mm}$ were likely to leave some area (volume) unprocessed between two subsequent laser pulses as well as between two subsequent laser tracks. On the contrary, selection of the minimum lateral $\left(\mathrm{D}_{\mathrm{L}}\right)$ and transverse $\left(\mathrm{D}_{\mathrm{T}}\right)$ distance of 0.1 $\mathrm{mm}$ between the subsequent laser pulses and laser tracks was based on physical and material considerations. $0.1 \mathrm{~mm}$ lateral $\left(\mathrm{D}_{\mathrm{L}}\right)$ and transverse $\left(\mathrm{D}_{\mathrm{T}}\right)$ distance provided maximum of $83 \%$ lateral $\left(\mathrm{O}_{\mathrm{L}}\right)$ and transverse $\left(\mathrm{O}_{\mathrm{T}}\right)$ overlap between two subsequent laser pulses and tracks, respectively. Maintenance of any smaller overlap distance than $0.1 \mathrm{~mm}$ (higher \% lateral $\left(\mathrm{O}_{\mathrm{L}}\right)$ and transverse $\left(\mathrm{O}_{\mathrm{T}}\right)$ overlap) due to thermal effects tends to create nearly a stationary drilling process with minimal material removal." 


\subsection{Physical Texture Measurements}

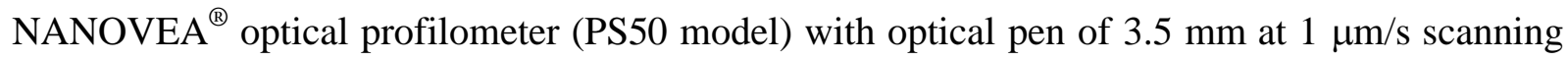
speed $\left(5 \times 5 \mathrm{~mm}^{2}\right.$ scan area) was used to measure the surface profile/topography/physical texture (Fig. 3). The surface parameters, namely, Sp (highest peak height or pileup height of the surface), Sv (highest valley depth or crater depth of the surface), and Sz (maximum height of the surface, $\mathrm{Sz}=\mathrm{Sp}+\mathrm{Sv}$ ) were evaluated by following the surface texture geometric product specifications (areal, ISO 25178-2:2012). A NANOVEA ${ }^{\circledR} 3$ D software was utilized for the postprocessing the raw data to obtain the amplitudes of theses parameters ( $\mathrm{Sp}, \mathrm{Sv}$ and $\mathrm{Sz}$ ) (Fig. 3a). The series of measurements along $\mathrm{X}-\mathrm{Z}$ planes obtained from the previous data were overlapped in order to estimate the mean surface profile (Fig. 3b) and corresponding surface parameters ( $\mathrm{Sp}$, $\mathrm{Sv}$ and Sz). To achieve higher statistical accuracy, a total of 5 surface profile measurements were taken for each machining condition. Based on this analysis, the average depth of cavities generated during laser machining was measured, and the resultant material removal rate (in $\left.\mathrm{mm}^{3} / \mathrm{min}\right)$ was calculated. The ratio of pileup height to crater depth (Sp/Sv) was specifically calculated in order to quantify the influence of pileup (Sp) and/or crater depth (Sv) over their corresponding surface parameter $(\mathrm{Sz})$ and material removal rates. Also, the experimentally measured surface parameter values $(\mathrm{Sz}=\mathrm{Sp}+\mathrm{Sv}=$ maximum height of the surface, $)$ were further used to validate the computational model of PM 3D laser machining.

This static method of post machining measurement approach was adopted due to its simplicity in measurements and calculations- for machining rate and although not accurate it likely to provide reasonable estimation and trend in material removal rate. On the contrary, laser being extremely rapid process (lasting for few micro- to milli-seconds) with development of very 
high temperature at the laser-material interaction region it is practically extremely difficult to conduct in-situ experimental measurements of the parameters for higher accuracy of material removal (machining) rate.

\subsection{Phase Transformation}

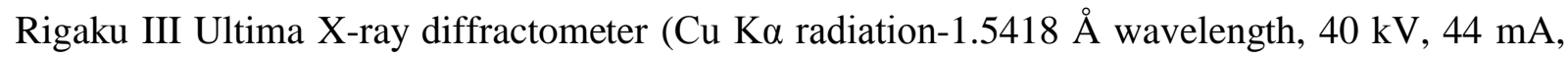
$2 \theta$ range of $20-90^{\circ}, 0.02^{\circ}$ step size, and 2 degree/minute scanning speed) was employed for $\mathrm{x}-$ ray diffraction (XRD) analysis of the laser machined and unmachined structural alumina samples using various laser machining conditions to evaluate the phase transformation. For phase identification, a standard international center for diffraction data (ICDD) from the joint committee of powder diffraction standards (JCPS) was utilized.

\section{$4 \quad$ Results and Discussions}

In the present efforts, the PM 3D laser machining was carried out to mill the $20 \mathrm{~mm} \times 20 \mathrm{~mm}$ cavity on the structural alumina by using a total of six processing conditions (effective laser energy densities $\left(E_{\text {eff }}\right)$ are $6.02,7.08,8.85,12.0,17.7,35.4 \times 10^{7} \mathrm{~J} / \mathrm{m}^{2}$ ). The effect of systematic increase in the corresponding effective laser energy density $\left(\mathrm{E}_{\text {eff }}\right)$ on the resultant surface parameters $(\mathrm{Sp}, \mathrm{Sv}$ and $\mathrm{Sz}$, where $\mathrm{Sz}=\mathrm{Sp}+\mathrm{Sv})$ are presented in Fig. 4. Based on the experimentally measured surface topographies for these particular processing conditions, the depths of cavities were measured and their resultant material removal rates were calculated for corresponding 3D laser machining conditions, and are summarized in Table 3.

For $6.02 \times 10^{7} \mathrm{~J} / \mathrm{m}^{2}$ laser processing condition $\left(\mathrm{D}_{\mathrm{L}}-\mathrm{D}_{\mathrm{T}}\right.$ : $\left.0.6 \mathrm{~mm}-0.6 \mathrm{~mm}, \mathrm{O}_{\mathrm{L}}-\mathrm{O}_{\mathrm{T}}: 0 \%-0 \%\right)$, the ratio of pileup height to crater depth $(\mathrm{Sp} / \mathrm{Sv})$ is 0.33 (Table 3), corresponding surface 
parameter (Sz) is $113.4 \pm 3.67 \mu \mathrm{m}$ (Fig.4a), and average depth of cavity generated during laser machining is $37.1 \pm 2.82 \mu \mathrm{m}$ (Table 2) with the material removal rate of $13.36 \pm 0.94 \mathrm{~mm}^{3} / \mathrm{min}$ (Table 3). However, for $7.08 \times 10^{7} \mathrm{~J} / \mathrm{m}^{2}$ laser processing condition, with a decrease in overlap (from $\mathrm{D}_{\mathrm{L}}-\mathrm{D}_{\mathrm{T}}$ : $0.6 \mathrm{~mm}-0.6 \mathrm{~mm}$ to $0.5 \mathrm{~mm}-0.5 \mathrm{~mm}, \mathrm{O}_{\mathrm{L}}-\mathrm{O}_{\mathrm{T}}: 0 \%-0 \%$ to $17 \%-17 \%$ ), the surface parameter (Sz) increased from $113.4 \pm 3.67$ to $127.5 \pm 1.96 \mu \mathrm{m}$ (Fig. 4b). It was previously observed for $7.08 \times 10^{7} \mathrm{~J} / \mathrm{m}^{2}$ laser processing condition [50] that the surface temperature barely reached vaporization temperature and mainly remained above the melting temperature for longer time. In these cases, therefore, material removal mechanism was mainly controlled by the liquid material flow due to surface tension and Marangoni convection. Since, for $7.08 \times 10^{7} \mathrm{~J} / \mathrm{m}^{2}$ laser processing condition $\left(\mathrm{D}_{\mathrm{L}}-\mathrm{D}_{\mathrm{T}}: 0.5 \mathrm{~mm}-0.5 \mathrm{~mm}, \mathrm{O}_{\mathrm{L}}-\mathrm{O}_{\mathrm{T}}: 17 \%-17 \%\right)$, the consecutive laser pulse was just $0.5 \mathrm{~mm}$ (with $17 \%$ overlay) away from the previously created pileup, re-solidification occurred on the previously created pileup and as a result the pileup height $(\mathrm{Sp})$ increased from $28.3 \pm 2.37$ to $49.2 \pm 0.85 \mu \mathrm{m}$ and surface parameter $(\mathrm{Sz})$ from $113.4 \pm 3.67$ to $127.5 \pm 1.96 \mu \mathrm{m}$ (Fig. 4). Thus, the increase in pileup height (Sp) compared to crater depth (Sv), led to the systematic increase in the $\mathrm{Sp} / \mathrm{Sv}$ ratio (from 0.33 to 0.63 ) (Table 3). Also, accordingly the average depth of cavity machined increased from $37.1 \pm 2.82$ to $124 \pm 4.68 \mu \mathrm{m}$ with the corresponding material removal rate from $13.36 \pm 0.94$ to $37.20 \pm 1.56 \mathrm{~mm}^{3} / \mathrm{min}$ (Table 3 ). Likewise, for laser processing conditions ranging from 8.85 to $17.7 \times 10^{7} \mathrm{~J} / \mathrm{m}^{2}\left(\mathrm{D}_{\mathrm{L}}-\mathrm{D}_{\mathrm{T}}\right.$ : $0.4 \mathrm{~mm}$ $0.4 \mathrm{~mm}$ to $0.2 \mathrm{~mm}-0.2 \mathrm{~mm}, \mathrm{O}_{\mathrm{L}}-\mathrm{O}_{\mathrm{T}}: 33 \%-33 \%$ to $67 \%-67 \%$ ), (Fig. $4 \mathrm{c}, 4 \mathrm{~d}$, and $4 \mathrm{e}$ ), the center-tocenter distance between two consecutive laser pulses are further reduced. Therefore, the successive laser pulse covered the majority of the previously created pileup region that mostly re-melted and/or partially vaporized the previous pileup and corresponding liquid material partially filled the previously created crater. This process, in turn, decreased the magnitudes of 
both the pileup as well as crater depth. Thus, both the pileup height $(\mathrm{Sp})$ and crater depth $(\mathrm{Sv})$ dramatically reduced thereby decreasing the surface parameter (Sz) from $127.5 \pm 1.96$ to $39.9 \pm$ $2.29 \mu \mathrm{m}$ (Table 3, Fig. 4). Also, in these all cases, the pileup height (Sp) gradually increased whereas the crater depth (Sv) gradually decreased thereby causing the systematic increase in the $\mathrm{Sp} / \mathrm{Sv}$ ratio (from 0.63 to 0.81 to 1.15 ) (Fig. 4).

On the contrary, for $\mathrm{E}_{\text {eff }}$ of $17.7 \times 10^{7} \mathrm{~J} / \mathrm{m}^{2}\left(\mathrm{D}_{\mathrm{L}}-\mathrm{D}_{\mathrm{T}}: 0.2 \mathrm{~mm}-0.2 \mathrm{~mm}, \mathrm{O}_{\mathrm{L}}-\mathrm{O}_{\mathrm{T}}: 67 \%-67 \%\right)$, the reduction in crater depth $(\mathrm{Sv})$ is more significant than pileup height $(\mathrm{Sp})$ causing the sudden drop in the $\mathrm{Sp} / \mathrm{Sv}$ ratio to 0.89 (Fig. $4 \mathrm{f}$ ). As the effective laser energy density ( $\left.\mathrm{E}_{\text {eff }}\right)$ increased to $35.4 \times 10^{7} \mathrm{~J} / \mathrm{m}^{2}$ and the overlap distance $\left(\mathrm{D}_{\mathrm{L}}-\mathrm{D}_{\mathrm{T}}\right)$ and overlap $\left(\mathrm{O}_{\mathrm{L}}-\mathrm{O}_{\mathrm{T}}\right)$ further decreased to 0.1 mm-0.1 mm and 83\%-83\%, respectively (Table 3), the successive laser pulse covered the majority portion of previously created crater region that entirely re-melted and/or partially vaporized. However, it was previously observed for $E_{\text {eff }}$ of $35.4 \times 10^{7} \mathrm{~J} / \mathrm{m}^{2}$ [50] that the surface temperature mostly remained above the vaporization temperature for a longer time to remove the significant amount of material via evaporation. This effect resulted in increased crater depth (Sv). The generation of vapor also led to the evaporation induced recoil pressure ejection of the remaining liquid material out of the crater for increased magnitude of pileup (Sp). For this laser processing condition $\left(E_{\text {eff }}=35.4 \times 10^{7} \mathrm{~J} / \mathrm{m}^{2}\right)$, the vaporization and re-solidification predominately happened on the previously created crater and pileup thereby leading to increase in crater depth $(\mathrm{Sv}=160 \pm 1.44 \mu \mathrm{m})$ and pileup height $(\mathrm{Sp}=113 \pm 1.12 \mu \mathrm{m})$, which in turn resulted in increase in the surface parameter $(\mathrm{Sz}=273.1 \pm 2.56 \mu \mathrm{m})$. Also, in this case, the crater depth $(\mathrm{Sv})$ being significantly higher than the pileup height (Sp), the $\mathrm{Sp} / \mathrm{Sv}$ ratio dropped to 0.71 (Table 3, Fig. 4). Furthermore, for $E_{\text {eff }}=35.4 \times 10^{7} \mathrm{~J} / \mathrm{m}^{2}$, the depth of cavity generated due to evaporation is $1000 \pm$ 
$8.11 \mu \mathrm{m}$ and corresponding material removal rate is $60 \pm 2.70 \mathrm{~mm}^{3} / \mathrm{min}$ (Table 3), which is highest among the presently employed machining conditions.

In the present efforts, the optical profilometer was used to measure the surface parameters $\left(\mathrm{Sp}, \mathrm{Sv}\right.$, and $\mathrm{Sz}$ ) for various laser beam overlap distances (lateral-transverse distance, $\mathrm{D}_{\mathrm{L}}-\mathrm{D}_{\mathrm{T}}=$ $0.1 \mathrm{~mm}-0.1 \mathrm{~mm}$ to $0.6 \mathrm{~mm}-0.6 \mathrm{~mm})$ and overlaps ((lateral-transverse overlap, $\mathrm{O}_{\mathrm{L}}-\mathrm{O}_{\mathrm{T}}$ : $0 \%-0 \%$ to $83 \%-83 \%$ ) to validate the computational model [48-50, 59]. For various processing conditions adopted during the present 3D laser machining efforts, the predicted and measured surface roughness parameters from the computational model and experimental observations are summarized in Table 4. The deviation among the computationally predicted and experimentally measured surface roughness parameters is within the range of $\pm 6 \%$, thereby indicating the reasonably successful validation of the computational model. However, the present deviation in the computational model may be due to the temperature dependent material properties and boundary conditions adopted from various sources in the open literature.

Thus among the set of laser machining conditions employed during the present efforts, effective laser energy $\left(\mathrm{E}_{\mathrm{eff}}\right)$ of $35.4 \times 10^{7} \mathrm{~J} / \mathrm{m}^{2}\left(\mathrm{D}_{\mathrm{L}}-\mathrm{D}_{\mathrm{T}}: 0.1 \mathrm{~mm}-0.1 \mathrm{~mm}, \mathrm{O}_{\mathrm{L}}-\mathrm{O}_{\mathrm{T}}: 83 \%-83 \%\right)$ was highly suitable for initial rough cuts (highest roughness, $S_{z}=273.1 \pm 2.56 \mu \mathrm{m}$ ) (Table 4) due essentially to the associated high material removal rate $\left(60 \pm 2.70 \mathrm{~mm}^{3} / \mathrm{min}\right)$ (Table 3$)$. Whereas, $\mathrm{E}_{\text {eff }}=17.7 \times 10^{7} \mathrm{~J} / \mathrm{m}^{2}\left(\mathrm{D}_{\mathrm{L}}-\mathrm{D}_{\mathrm{T}}: 0.2 \mathrm{~mm}-0.2 \mathrm{~mm}, \mathrm{O}_{\mathrm{L}}-\mathrm{O}_{\mathrm{T}}: 67 \%-67 \%\right)$ laser machining parameter although associated with a relatively slow machining rate $\left(22.92 \mathrm{~mm}^{3} / \mathrm{min}\right)$ it is highly suitable for final machining with low surface roughness $(39.9 \pm 2.29 \mu \mathrm{m}$, Table 3). Hence, it was evidently demonstrated that the laser can be employed for various machining stages such as initial rough cut followed by final finishing cut for optimal combination of machining rate and 
surface roughness. Nonetheless, it is equally important to machine the structural ceramic without causing any phase transformation and cracking due to the thermal stresses since it can adversely affect their structural performance. Extensive XRD analysis revealed that the all the peaks of laser machined alumina matched with $\alpha-\mathrm{Al}_{2} \mathrm{O}_{3}$ of the as-received alumina, confirming that no phase transformation occurred under the presently employed 3D laser machining conditions. Furthermore, although few minor micro-cracks were observed on the surface of laser machined alumina, the number density and the average length/depth of such micro-cracks appeared to depend upon the combination of laser machining parameters. Hence, it is possible to suppress their generation and/or control their number density and average length/depth by controlling the thermal conditions through selection of appropriate/optimum set of laser machining parameters. Nonetheless, the detailed analysis of thermal stresses/residual stresses generated during 3D laser machining conducted using the set of parameters employed in the work described above can be found in recently published work by the authors [60].

The PM 3D laser machining developed in the present efforts, was further validated via laser turning operation. An alumina rod (diameter $=19.05 \mathrm{~mm}$, length $=75 \mathrm{~mm})$ was machined using the optimal parameters identified in the present efforts (effective laser energy density $\left(\mathrm{E}_{\mathrm{eff}}\right)$ of $\left.17.7 \times 10^{7} \mathrm{~J} / \mathrm{m}^{2}, \mathrm{D}_{\mathrm{L}}-\mathrm{D}_{\mathrm{T}}: 0.2 \mathrm{~mm}-0.2 \mathrm{~mm}, \mathrm{O}_{\mathrm{L}}-\mathrm{O}_{\mathrm{T}}: 67 \%-67 \%\right)$. The laser turning setup employed in this operation is presented in Fig. 5. The single pass turning operation resulted in generation of the surface parameters $(\mathrm{Sz})$ of $40 \pm 0.81 \mu \mathrm{m}$ and depth of cavity of $200 \pm 1.35 \mu \mathrm{m}$ with the machining rate (material removal rate) of $22.92 \pm 1.80 \mathrm{~mm}^{3} / \mathrm{min}$. 


\section{$5 \quad$ Conclusion}

It was observed that the surface parameter (Sz) initially increased from $113.4 \pm 3.67$ to $127.5 \pm$ $1.96 \mu \mathrm{m}$ for effective laser energy density $\left(E_{\text {eff }}\right)$ of 6.02 to $7.08 \times 10^{7} \mathrm{~J} / \mathrm{m}^{2}\left(\mathrm{D}_{\mathrm{L}}-\mathrm{D}_{\mathrm{T}}: 0.6 \mathrm{~mm}-0.6 \mathrm{~mm}\right.$ to $0.5 \mathrm{~mm}-0.5 \mathrm{~mm}, \mathrm{O}_{\mathrm{L}}-\mathrm{O}_{\mathrm{T}}: 0 \%-0 \%$ to $17 \%-17 \%$ ), respectively, and then decreased from $127.5 \pm$ $1.96 \mu \mathrm{m}$ to $39.9 \pm 2.29 \mu \mathrm{m}$ for $\mathrm{E}_{\text {eff }}$ of 7.08 to $17.7 \times 10^{7} \mathrm{~J} / \mathrm{m}^{2}\left(\mathrm{D}_{\mathrm{L}}-\mathrm{D}_{\mathrm{T}}: 0.5 \mathrm{~mm}-0.5 \mathrm{~mm}\right.$ to $0.2 \mathrm{~mm}$ $0.2 \mathrm{~mm}, \mathrm{O}_{\mathrm{L}}-\mathrm{O}_{\mathrm{T}}: 17 \%-17 \%$ to $67 \%-67 \%$ ), respectively and finally increased to $273.1 \pm 2.56 \mu \mathrm{m}$ for $\mathrm{E}_{\text {eff }}$ of $35.4 \times 10^{7} \mathrm{~J} / \mathrm{m}^{2}\left(\mathrm{D}_{\mathrm{L}}-\mathrm{D}_{\mathrm{T}}: 0.1 \mathrm{~mm}-0.1 \mathrm{~mm}, \mathrm{O}_{\mathrm{L}}-\mathrm{O}_{\mathrm{T}}: 83 \%-83 \%\right)$. The higher material removal rate $\left(60 \pm 2.70 \mathrm{~mm}^{3} / \mathrm{min}\right)$ was experienced for the $35.4 \times 10^{7} \mathrm{~J} / \mathrm{m}^{2}\left(\mathrm{D}_{\mathrm{L}}-\mathrm{D}_{\mathrm{T}}: 0.1 \mathrm{~mm}\right.$ $\left.0.1 \mathrm{~mm}, \mathrm{O}_{\mathrm{L}}-\mathrm{O}_{\mathrm{T}}: 83 \%-83 \%\right)$ laser machining conditions whereas finer surface finish $(39.9 \pm 2.29$ $\mu \mathrm{m})$ was generated with the $17.7 \times 10^{7} \mathrm{~J} / \mathrm{m}^{2}\left(\mathrm{D}_{\mathrm{L}}-\mathrm{D}_{\mathrm{T}}: 0.2 \mathrm{~mm}-0.2 \mathrm{~mm}, \mathrm{O}_{\mathrm{L}}-\mathrm{O}_{\mathrm{T}}: 67 \%-67 \%\right)$ laser machining condition. These variations in the magnitude of surface finish and material removal rate are mainly attributed to the laser processing conditions ( $\left.\mathrm{E}_{\mathrm{eff}}\right)$ and associated physical phenomena such as Marangoni convection, recoil pressure, and surface tension. For the lower $\mathrm{E}_{\text {eff }}$ of $6.02 \times 10^{7} \mathrm{~J} / \mathrm{m}^{2}\left(\mathrm{D}_{\mathrm{L}}-\mathrm{D}_{\mathrm{T}}: 0.6 \mathrm{~mm}-0.6 \mathrm{~mm}, \mathrm{O}_{\mathrm{L}}-\mathrm{O}_{\mathrm{T}}: 0 \%-0 \%\right)$, the individual pileup is distinctly separated due the confinement of material flow around the crater. Whereas, for $\mathrm{E}_{\text {eff }}$ of 7.08 to $17.7 \times 10^{7} \mathrm{~J} / \mathrm{m}^{2}$ ( $\mathrm{D}_{\mathrm{L}}-\mathrm{D}_{\mathrm{T}}: 0.5 \mathrm{~mm}-0.5 \mathrm{~mm}$ to $0.2 \mathrm{~mm}-0.2 \mathrm{~mm}, \mathrm{O}_{\mathrm{L}}-\mathrm{O}_{\mathrm{T}}: 17 \%-17 \%$ to $\left.67 \%-67 \%\right)$, the successive pileups and/or craters partially to fully merged with the previous pileup and craters mainly due to Marangoni convection and surface tension causing reduction in the magnitudes of the pileup (Sp) crater depth (Sv) and surface parameter (Sz). On the contrary, for $\mathrm{E}_{\text {eff }}$ of $35.4 \times 10^{7}$ $\mathrm{J} / \mathrm{m}^{2}\left(\mathrm{D}_{\mathrm{L}}-\mathrm{D}_{\mathrm{T}}: 0.1 \mathrm{~mm}-0.1 \mathrm{~mm}, \mathrm{O}_{\mathrm{L}}-\mathrm{O}_{\mathrm{T}}: 83 \%-83 \%\right)$, the material removal mechanism was mainly via evaporation and evaporation induced recoil pressure that created the deeper crater $(\mathrm{Sv}=$ $160.1 \pm 1.44 \mu \mathrm{m})$ and higher pileup $(\mathrm{Sp}=113 \pm 1.12 \mu \mathrm{m})$, and thus higher surface parameter $(\mathrm{Sz}$ 
$=273.1 \pm 2.56 \mu \mathrm{m})$. A close agreement and a similar trend were observed between the computationally predicted experimentally observations surface values. The present model can also be extended to predict the surface topography for any other structural ceramics subjected to various laser processing conditions.

\section{Acknowledgements}

The authors, NBD and HDV would like to acknowledge the financial support from the National Science Foundation (NSF-CMMI 1010494). The authors appreciate Dr. Sandra K.S. Boetcher of Embry-Riddle Aeronautical University for helpful discussions on the multiphysics computational model. Authors also acknowledge the Center for Advanced Research Technology (CART) at the University of North Texas for providing the characterization facilities. In addition, the authors wish to thank Dr. Radovan Kovacevic, Southern Methodist University, for providing the research facilities for surface roughness measurement.

\section{References:}

[1] Samant AN, Dahotre NB. Laser machining of structural ceramics-A review. Journal of the European Ceramic Society 2009; 29: 969-993

[2] Samant AN. Laser Machining of Structural Ceramics: Computational and Experimental Analysis. PhD Dissertation, University of Tennessee 2009

[3] Tuersley IP, Jawaid A, Pashby IR. Review: Various methods of machining advanced ceramic materials. Journal of Materials Processing Technology 1994; 42: 377-390

[4] Vikulin VV, Kelina IY, Shatalin AS, Rusanova LN. Advanced ceramic structural materials. Refractories and Industrial Ceramics 2004; 45: 383-386

[5] Dahotre NB, Samant AN. Laser machining of advanced materials. London, UK; Boca Raton, Fla.: CRC Press/Balkema. 2011 
[6] Shen JY, Luo CB, Zeng WM, Xu XP, Gao YS. Ceramics grinding under the condition of constant pressure. Journal of Materials Processing Technology 2002; 129: 176-181

[7] König W, Wagemann A. Machining of ceramic components - process-technological potentials. National Institute of Standards and Technology -NIST-: Machining of Advanced Materials. Proceedings: MD-Vol. 45, PED-Vol. 66. (Special Publications - United States Department of Commerce) 1993; 45: 3-16

[8] Chryssolouris G, Anifantis N, Karagiannis S. Laser assisted machining: An overview. Journal of Manufacturing Science and Engineering, Transactions of the ASME 1997; 119: 766-769

[9] Kacar E, Mutlu M, Akman E, Demir A, Candan L, Canel T, Gunay V, Sinmazcelik T. Characterization of the drilling alumina ceramic using Nd:YAG pulsed laser. Journal of Materials Processing Technology 2009; 209: 2008-2014

[10] Harimkar SP, Dahotre NB. Effect of laser fluence on surface microstructure of alumina ceramic. Advances in Applied Ceramics 2006; 105: 304-308

[11] Triantafyllidis D, Li L, Stott FH. Surface treatment of alumina-based ceramics using combined laser sources. Applied Surface Science 2002; 186: 140-144

[12] Koepke BG, Stokes RJ. A study of grinding damage in magnesium oxide single crystals. Journal of Materials Science 1970; 5: 240-247

[13] Kirchner HP. Damage Penetration at Elongated Machining Grooves in Hot-Pressed Si3N4. Journal of the American Ceramic Society 1984; 67: 127-132

[14] Conway JC, Kirchner HP. Crack Branching as a Mechanism of Crushing During Grinding. Journal of the American Ceramic Society 1986; 69: 603-607

[15] Dahotre NB, Harimkar SP. Laser fabrication and machining of materials. New York, N.Y.: Springer. 2008

[16] Kannatey-Asibu E. Principles of laser materials processing. Hoboken, N.J.: Wiley. 2009

[17] Chryssolouris G. Laser machining : theory and practice. New York: Springer-Verlag. 1991

[18] Salonitis K, Stavropoulos P, Stournaras A, Chryssolouris G. $\mathrm{CO}_{2}$ Laser cutting of aluminium. Proceeding of the 5th Laser Assisted Net Shape Engineering 2007: 825-835

[19] Stavropoulos P, Salonitis K, Stournaras A, Euthimiou K, Chryssolouris G. Molecular dynamics simulation of laser ablation of iron. Proceedings of the 10th CIRP International Workshop on Modeling of Machining Operations 2007: 549-553 
[20] Stournaras A, Salonitis K, Stavropoulos P, Chryssolouris G. Finite element thermal analysis of pulsed laser drilling process. Proceedings of the 10th CIRP International Workshop on Modeling of Machining Operations 2007: 563-570

[21] Dubey AK, Yadava V. Laser beam machining-A review. International Journal of Machine Tools and Manufacture 2008; 48: 609-628

[22] Rozzi JC, Pfefferkorn FE, Shin YC, Incropera FP. Experimental evaluation of the laser assisted machining of silicon nitride ceramics. Journal of Manufacturing Science and Engineering 2000; 122: 666-670

[23] Pham D, Dimov S, Petkov P. Laser milling of ceramic components. International Journal of Machine Tools and Manufacture 2007; 47: 618-626

[24] Wu Y, Choy K, Hench LL. Preparation of $\alpha$-Alumina Platelets by Laser Scanning. Journal

of the American Ceramic Society 2004; 87: 1606-1608

[25] Wu Y, Du J, Choy K, Hench LL. Laser densification of alumina powder beds generated using aerosol assisted spray deposition. Journal of the European Ceramic Society 2007; 27: $4727-4735$

[26] Guo D, Cai K, Yang J, Huang Y. Spatter-free laser drilling of alumina ceramics based on gelcasting technology. Journal of the European Ceramic Society 2003; 23: 1263-1267

[27] Cai K, Guo D, Huang Y, Yang J. Solid freeform fabrication of alumina ceramic parts through a lost mould method. Journal of the European Ceramic Society 2003; 23: 921-925

[28] Nowak KM, Baker HJ, Hall DR. Efficient laser polishing of silica micro-optic components. Applied Optics 2006; 45: 162-171

[29] Sedore B. Laser Welding of Alumina Ceramic Substrates with Two Fixed Beams 2013

[30] Samant AN, Dahotre NB. Computational predictions in single-dimensional laser machining of alumina. International Journal of Machine Tools and Manufacture 2008; 48: 1345-1353

[31] Samant AN, Dahotre NB. Differences in physical phenomena governing laser machining of structural ceramics. Ceramics International 2009; 35: 2093-2097

[32] Harimkar SP, Samant AN, Dahotre NB. Temporally evolved recoil pressure driven melt infiltration during laser surface modifications of porous alumina ceramic. Journal of Applied Physics 2007; 101: 054911-054911-7 
[33] Sun S, Durandet Y, Brandt M. Parametric investigation of pulsed Nd: YAG laser cladding of stellite 6 on stainless steel. Surface and Coatings Technology 2005; 194: 225-231

[34] Lawrence J, Low DKY, Pou J, Toyserkani E. Advances in Laser Materials Processing Technology. Cambridge: Woodhead Publishing Ltd. 2010

[35] Hanon MM, Akman E, Genc Oztoprak B, Gunes M, Taha ZA, Hajim KI, Kacar E, Gundogdu O, Demir A. Experimental and theoretical investigation of the drilling of alumina ceramic using Nd:YAG pulsed laser. Optics \& Laser Technology 2012; 44: 913-922

[36] Rozzi JC, Pfefferkorn FE, Incropera FP, Shin YC. Transient, three-dimensional heat transfer model for the laser assisted machining of silicon nitride: I. Comparison of predictions with measured surface temperature histories. International Journal of Heat and Mass Transfer 2000; 43: $1409-1424$

[37] Rozzi JC, Pfefferkorn FE, Incropera FP, Shin YC. Transient thermal response of a rotating cylindrical silicon nitride workpiece subjected to a translating laser heat source, part I:

comparison of surface temperature measurements with theoretical results. Journal of heat transfer 1998; 120: 899-906

[38] Tian Y, Shin YC. Thermal modeling for laser-assisted machining of silicon nitride ceramics with complex features. Journal of manufacturing science and engineering 2006; 128: 425-434

[39] Yilbas B. Laser heating process and experimental validation. International Journal of Heat and Mass Transfer 1997; 40: 1131-1143

[40] Yilbas B, Aleem BA. Dross formation during laser cutting process. Journal of Physics D: Applied Physics 2006; 39: 1451

[41] Yilbaş BS. Experimental investigation into $\mathrm{CO}<\mathrm{sub}>2</ \mathrm{sub}>$ laser cutting parameters. Journal of Materials Processing Technology 1996; 58: 323-330

[42] Lei S, Shin YC, Incropera FP. Experimental investigation of thermo-mechanical characteristics in laser-assisted machining of silicon nitride ceramics. Journal of Manufacturing Science and Engineering 2001; 123: 639-646

[43] Smith R, Surprenant R, Kaminski D. Fracture characteristics of an aluminum oxide ceramic during continuous wave carbon dioxide laser cutting. Journal of laser applications 1992; 4: 25-32

[44] Demir P, Kacar E, Akman E, Demir A. Single Pulse Laser Ablation of AISI 316L Stainless Steel Surface Using Nd: YAG Laser Irradiation. Acta Physica Polonica, A. 2014; 125

[45] Yan Y, Li L, Sezer K, Whitehead D, Ji L, Bao Y, Jiang Y. Experimental and theoretical investigation of fibre laser crack-free cutting of thick-section alumina. International Journal of Machine Tools and Manufacture 2011; 51: 859-870 
[46] Gilbert T, Krstic VD, Zak G. Machining of aluminium nitride with ultra-violet and nearinfrared Nd: YAG lasers. Journal of Materials Processing Technology 2007; 189: 409-417

[47] Islama MU, Campbella G. Laser machining of ceramics: a review. Materials and Manufacturing Processes 1993; 8: 611-630

[48] Vora HD, Santhanakrishnan S, Harimkar SP, Boetcher SKS, Dahotre NB. Evolution of surface topography in one-dimensional laser machining of structural alumina. Journal of the European Ceramic Society 2012; 32: 4205-4218

[49] Vora HD, Santhanakrishnan S, Harimkar SP, Boetcher SKS, Dahotre NB. One-dimensional multipulse laser machining of structural alumina: evolution of surface topography. The International Journal of Advanced Manufacturing Technology 2013; 68: 69-83

[50] Vora HD, Dahotre NB. Laser Machining of Structural Alumina: Influence of Moving Laser Beam on the Evolution of Surface Topography. International Journal of Applied Ceramic Technology 2014: 1-14

[51] Kannatey-Asibu E. Principles of laser materials processing. Hoboken, N.J.: Wiley. 2009

[52] Samant AN, Dahotre NB. Differences in physical phenomena governing laser machining of structural ceramics. Ceramics International 2009; 35: 2093-2097

[53] COMSOL. Marangoni convection model. COMSOL Multiphysics model library 2011; V $4.2 \mathrm{a}$

[54] Paradis P, Ishikawa T. Surface tension and viscosity measurement of liquid and undercooled alumina by contactless techniques. Japanese Journal of Applied Physics 2005; 44: 5082-5085

[55] Sussman M, Smereka P, Osher S. A Level Set Approach for Computing Solutions to Incompressible Two-Phase Flow. Journal of Computational Physics 1994; 114: 146-159

[56] Gitzen WH. Alumina as a ceramic material. Columbus, Ohio: American Ceramic Society. 1970

[57] Quintero F, Varas F, Pou J, Lusquiños F, Boutinguiza M, Soto R, Pérez-Amor M. Theoretical analysis of material removal mechanisms in pulsed laser fusion cutting of ceramics. Journal of Physics D: Applied Physics 2005; 38: 655-666

[58] Kolev NI. Multiphase flow dynamics 5. Nuclear thermal hydraulics. Berlin; Heidelberg; New York; Barcelona; Hong Kong; London; Milan; Paris; Tokyo: Springer. 2011

[59] Vora HD, Dahotre NB. Laser machining of structural ceramics. American Ceramic Society Bulletin 2013; 92: 29-30 
[60] Vora HD, Dahotre NB. Multiphysics Theoretical Evaluation of Thermal Stresses in Laser Machined Structural Alumina. Lasers in Manufacturing and Materials Processing 2015; 2: 1-23 


\section{Figure Captions}

\begin{tabular}{|c|c|}
\hline $\begin{array}{l}\text { Fig } \\
\text { ure \# }\end{array}$ & Title \\
\hline Fig & $\begin{array}{l}\text { 3D laser machining (a) schematic of pulse mode, and (b) the effect of } \\
\text { physical nature of laser }\end{array}$ \\
\hline .2 & $\begin{array}{l}\text { Multistep modeling approach to predict the parameters related to surface } \\
\text { profile (topography) and material removal during PM 3D laser machining }\end{array}$ \\
\hline Fig & $\begin{array}{l}\text { Schematic of surface profile measurements for PM 3D laser machining (a) } \\
\text { 3D surface morphology and corresponding parameters (Sp, Sv and Sz), (b) mean } \\
\text { surface profile of measurements along X-Z plane }\end{array}$ \\
\hline .4 & $\begin{array}{l}\text { Experimentally measured surface parameters (ISO 25178) for various laser } \\
\text { machining conditions as function of effective laser energy density }\end{array}$ \\
\hline .5 & Laser machined (turned) alumina rod \\
\hline
\end{tabular}




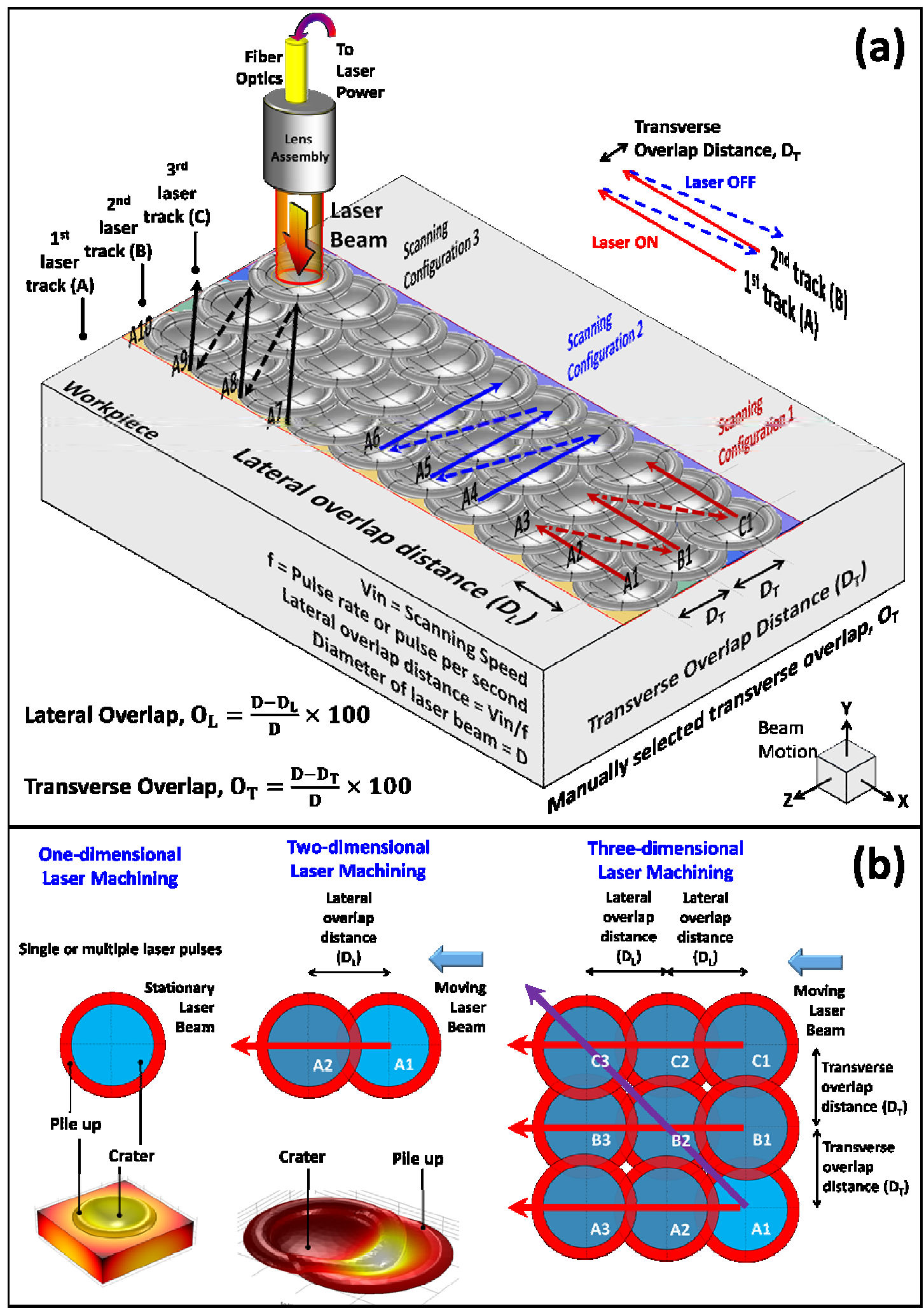


Fig. 13 D laser machining (a) schematic of pulse mode, and (b) the effect of physical nature of laser 


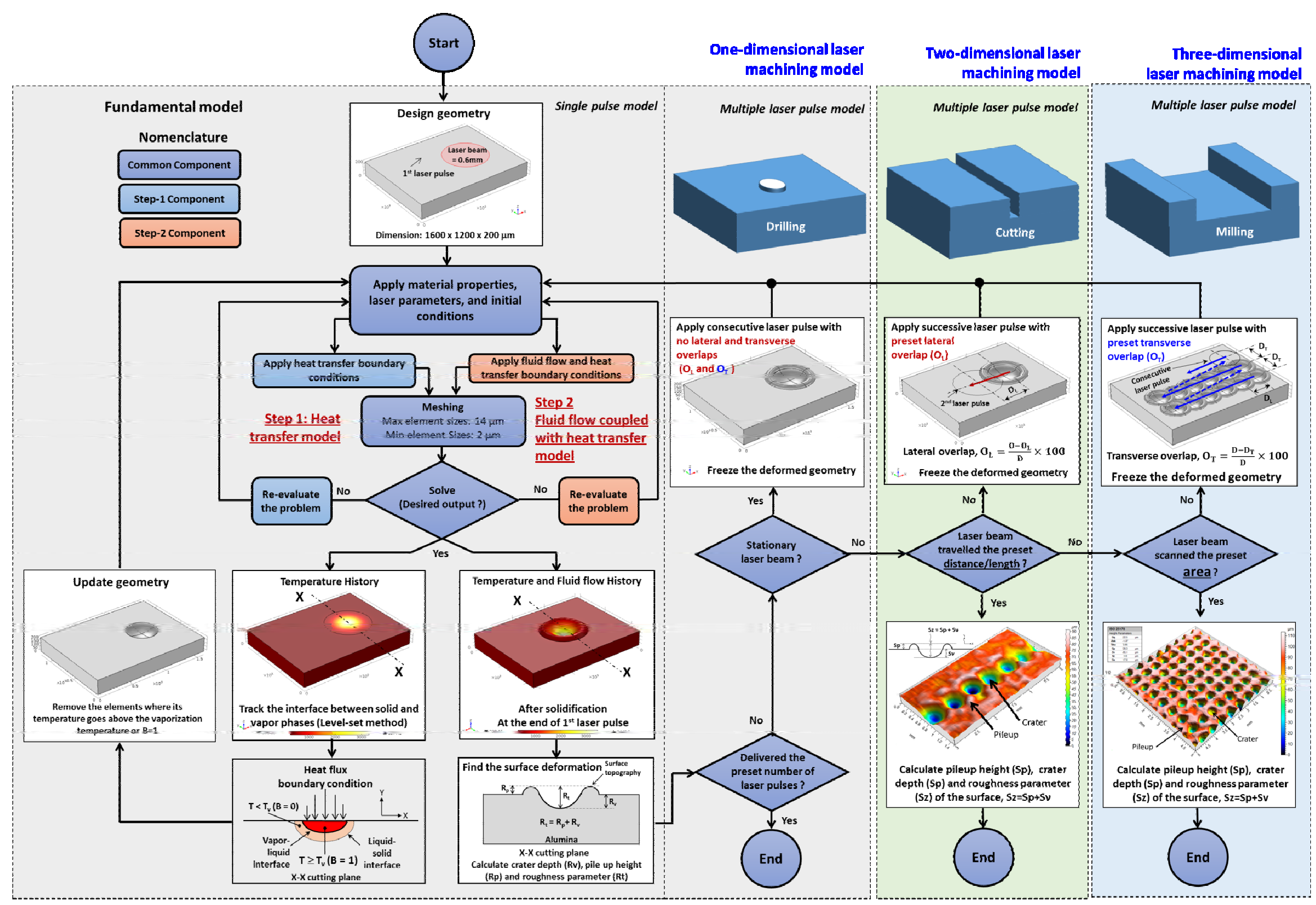

Page 28 of 38 
Fig. 2 Multistep modeling approach to predict the parameters related to surface profile (topography) and material removal during PM 3D laser machining 


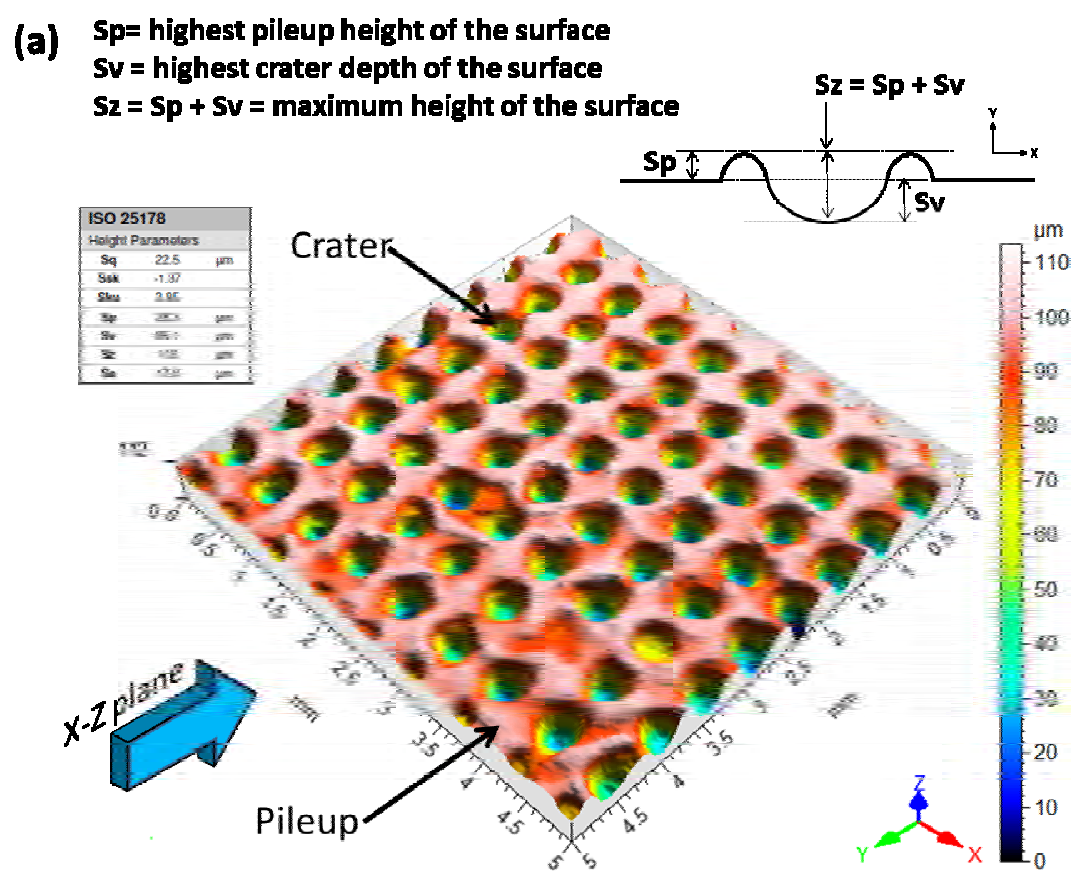

(b)

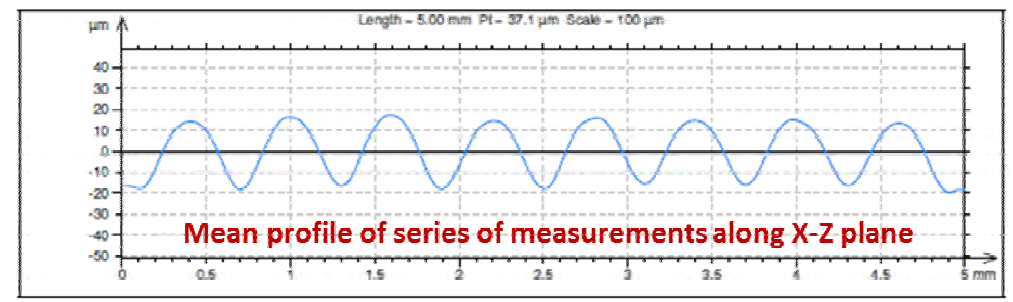

Fig. 3 Schematic of surface profile measurements for PM 3D laser machining (a) 3D surface morphology and corresponding parameters (Sp, Sv and Sz), (b) mean surface profile of measurements along $\mathrm{X}-\mathrm{Z}$ plane 


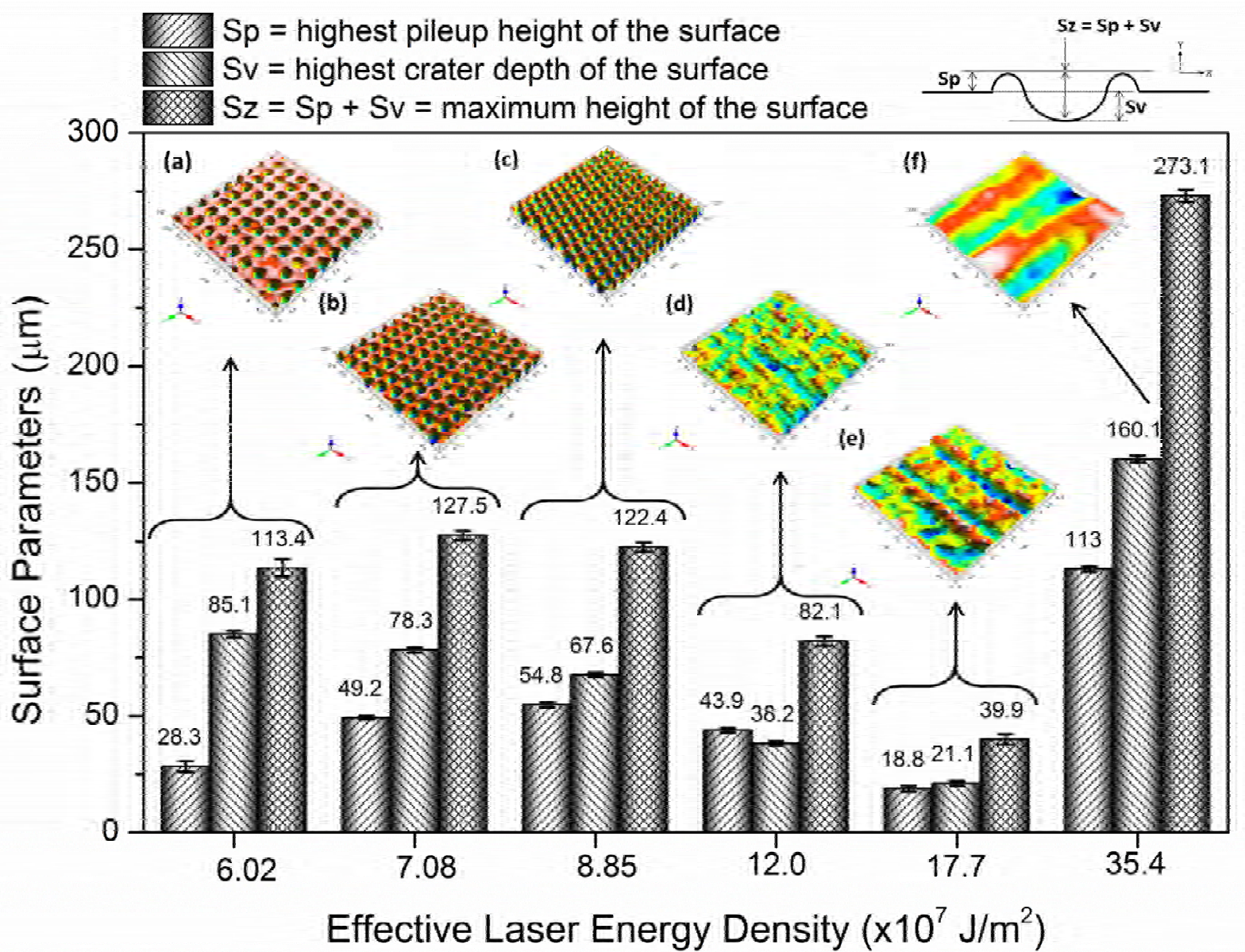

Fig. 4 Experimentally measured surface parameters (ISO 25178) for various laser machining conditions as function of effective laser energy density 


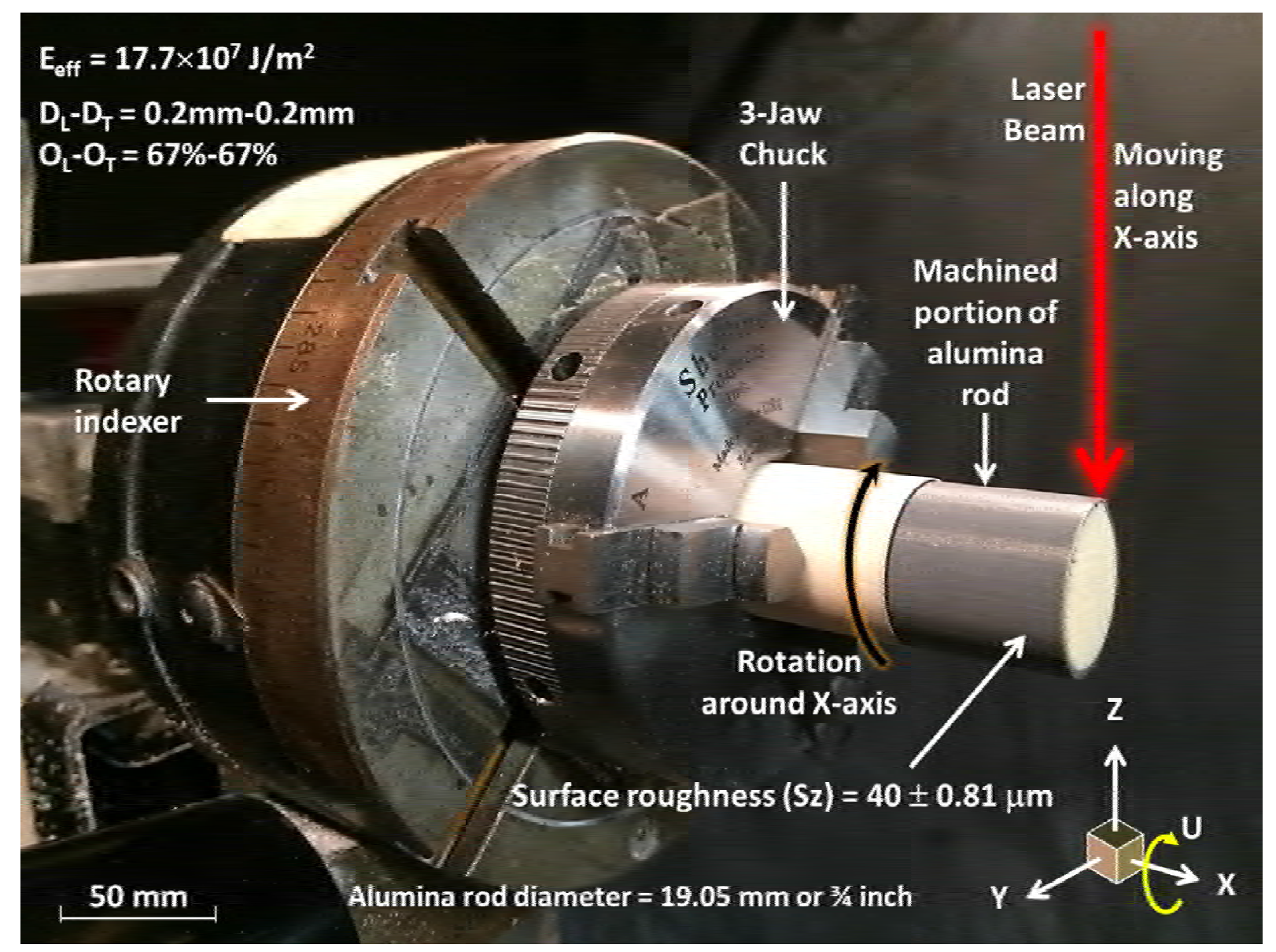

Fig. 5 Laser machined (turned) alumina rod 


\section{Tables Captions}

\begin{tabular}{|c|c|}
\hline Table & Title \\
\hline $\begin{array}{r}\text { Table } \\
1\end{array}$ & $\begin{array}{l}\text { Selective governing equations and important boundary conditions for } \\
\text { multiphysics computational model }\end{array}$ \\
\hline $\begin{array}{l}\text { Table } \\
2\end{array}$ & Laser parameters for PM 3D machining \\
\hline $\begin{array}{r}\text { Table } \\
3\end{array}$ & $\begin{array}{l}\text { Experimentally measured attributes of machined cavities during PM 3D } \\
\text { laser machining }\end{array}$ \\
\hline Table & $\begin{array}{l}\text { Computationally predicted and experimentally measured surface } \\
\text { roughness for PM 3D laser machining conditions }\end{array}$ \\
\hline
\end{tabular}




\section{Tables Captions}

\begin{tabular}{|l|l|}
\hline Table \# & Title \\
\hline Table 1 & $\begin{array}{l}\text { Selective governing equations and important boundary conditions for multiphysics } \\
\text { computational model }\end{array}$ \\
\hline Table 2 & Laser parameters for PM 3D machining \\
\hline Table 3 & $\begin{array}{l}\text { Experimentally measured attributes of machined cavities during PM 3D laser } \\
\text { machining }\end{array}$ \\
\hline Table 4 & $\begin{array}{l}\text { Computationally predicted and experimentally measured surface roughness for PM } \\
\text { 3D laser machining conditions }\end{array}$ \\
\hline
\end{tabular}


Table 1 Selective governing equations and boundary conditions for multiphysics computational model

\begin{tabular}{|c|c|c|c|}
\hline Boundary condition & Equation & \# & Reference \\
\hline $\begin{array}{l}\text { Heat flux, natural convection } \\
\text { cooling and radiation }\end{array}$ & $\begin{array}{l}\rho \mathrm{c}_{\mathrm{p}}\left[\frac{\partial \mathrm{T}}{\partial \mathrm{t}}\right]=\mathrm{k}\left[\left(\frac{\partial^{2} \mathrm{~T}}{\partial \mathrm{x}^{2}}\right)+\left(\frac{\partial^{2} \mathrm{~T}}{\partial \mathrm{y}^{2}}\right)+\left(\frac{\partial^{2} \mathrm{~T}}{\partial z^{2}}\right)\right], \\
-\mathrm{k} \nabla \mathrm{T}=-\varphi \mathrm{P}_{\mathrm{g}}+\mathrm{h}\left[\mathrm{T}-\mathrm{T}_{\mathrm{a}}\right]+\varepsilon \sigma\left[\mathrm{T}^{4}-\mathrm{T}_{\mathrm{a}}^{4}\right] \\
\text { where, } \varphi=1 \text { for } 0 \leq \mathrm{t} \leq \mathrm{P}_{\mathrm{w}} \text { and } \varphi=0 \text { for } \mathrm{t} \geq \mathrm{P}_{\mathrm{w}}\end{array}$ & (1) and (2) & [48-51] \\
\hline $\begin{array}{l}\text { A verage laser power density } \\
\text { in Gaussian distribution } \\
\left(\mathrm{W} / \mathrm{m}^{2}\right)\end{array}$ & $\mathrm{P}_{\mathrm{g}}=\mathrm{A}\left[\frac{\mathrm{F}_{\mathrm{p}}}{\mathrm{P}_{\mathrm{w}}\left(\frac{\mathrm{m}}{4} \mathrm{D}^{2}\right)}\right] \cdot \exp \left[-\left(\frac{\left(\mathrm{x}-\mathrm{x}_{\mathrm{r}}\right)}{2 \sigma^{2}}\right)\right] \cdot \exp \left[-\left(\frac{\left(\mathrm{y}-\mathrm{y}_{\mathrm{r}}\right)^{2}}{2 \sigma^{2}}\right)\right]$ & (3) & {$[48-50]$} \\
\hline \multirow{3}{*}{ Level set method } & $B=1 \quad$ for $\left(T>T_{x}+\Delta T\right)$ & $(4)$ & {$[55]$} \\
\hline & $\mathrm{B}=\frac{\left(\mathrm{T}-\mathrm{T}_{\mathrm{x}}+\Delta \mathrm{T}\right)}{2 \Delta \mathrm{T}}$ for $\left(\mathrm{T}_{\mathrm{x}}-\Delta \mathrm{T}\right) \leq \mathrm{T} \leq\left(\mathrm{T}_{\mathrm{x}}+\Delta \mathrm{T}\right)$ & (5) & [55] \\
\hline & $B=0 \quad$ for $\left(T<T_{x}-\Delta T\right)$ & (6) & [55] \\
\hline Volume force & $\mathrm{pga}\left(\mathrm{T}-\mathrm{T}_{\mathrm{m}}\right)$ given by Boussinesq approximation & (7) & {$[48-50]$} \\
\hline Recoil pressure & $\mathrm{P}_{\mathrm{r}}=\left(\mathrm{P}_{\mathrm{g}}\right) \frac{1.69}{\sqrt{\mathrm{L}_{\mathrm{v}}}}\left[\frac{\sqrt{\left(\frac{\mathrm{k}_{\mathrm{v}} \mathrm{T}_{\mathrm{g}}}{\mathrm{M}_{\mathrm{v}} \mathrm{L}_{\mathrm{v}}}\right)}}{1+2.2\left(\frac{\mathrm{k} \cdot \mathrm{T}_{\mathrm{g}}}{\mathrm{M}_{\mathrm{v}} \mathrm{L}_{\mathrm{v}}}\right)^{2}}\right]$ only when $\mathrm{T} \geq \mathrm{T}_{\mathrm{v}}$ & (8) & $\begin{array}{l}{[48-50,} \\
52]\end{array}$ \\
\hline Surface tension & $\operatorname{test}(u) *\left[\frac{\partial Y}{\partial T} \frac{\partial T}{\partial x}\right]$, test $(v) *\left[\frac{\partial_{Y}}{\partial T} \frac{\partial T}{\partial y}\right]$, test $(w) *\left[\frac{\partial_{Y}}{\partial T} \frac{\partial T}{\partial x}\right]$ & $\begin{array}{l}(9),(10) \\
\text { and }(11)\end{array}$ & $\begin{array}{l}{[48-50,} \\
54]\end{array}$ \\
\hline \multicolumn{4}{|c|}{ 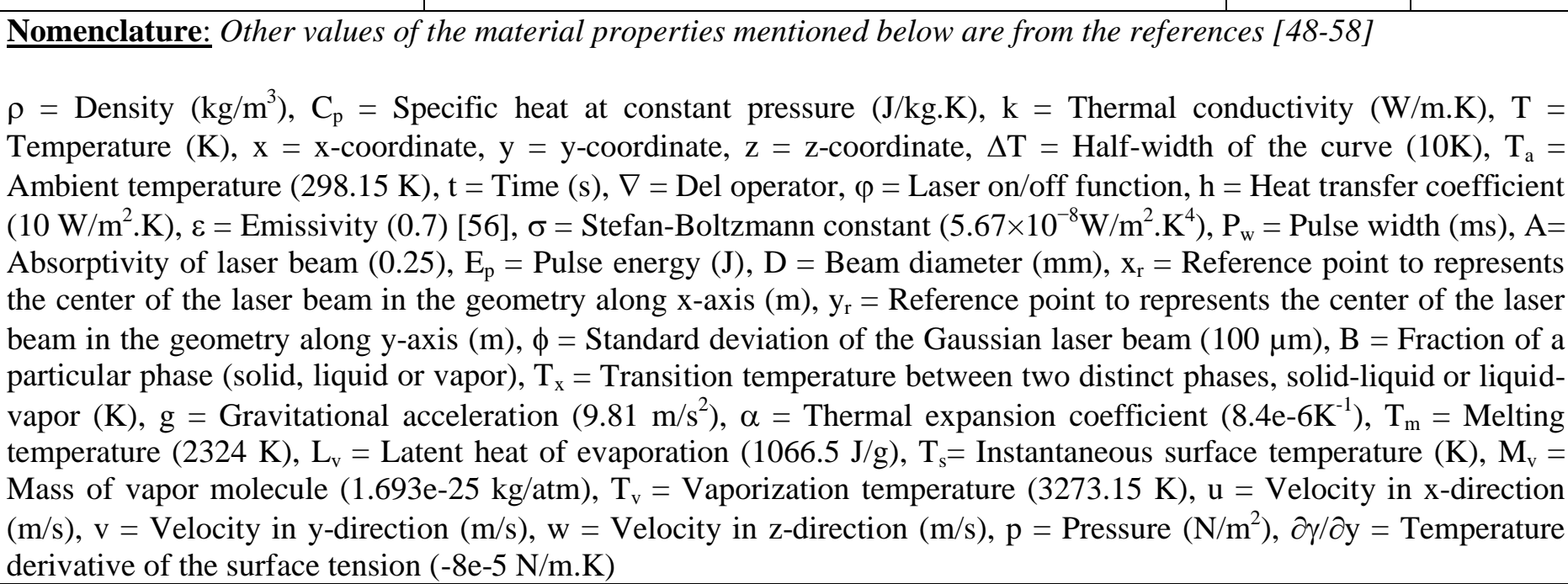 } \\
\hline
\end{tabular}


Table 2 Laser parameters for PM 3D machining

\begin{tabular}{|c|c|c|}
\hline Parameter & Nomenclature & Value (units) \\
\hline Pulse energy & $E_{p}$ & $1(\mathrm{~J})$ \\
\hline Pulse width & $\mathrm{P}_{\mathrm{w}}$ & 0.5 (ms) \\
\hline $\begin{array}{l}\text { Beam diameter at the focus on } \\
\text { sample surface }\end{array}$ & D & $0.6(\mathrm{~mm})$ \\
\hline Pulse rate or pulses per second & $f$ & $17,20,25,34,50,100$ pulses \\
\hline Scanning speed & Vin & $10(\mathrm{~mm} / \mathrm{s})$ \\
\hline $\begin{array}{l}\text { Lateral overlap distance or distance } \\
\text { between two laser pulses }\end{array}$ & $D_{L}=V \mathrm{in} / \mathrm{f}$ & $\begin{array}{l}0.6,0.5,0.4,0.3,0.2,0.1(\mathrm{~mm}) \\
\text { respectively }\end{array}$ \\
\hline Lateral overlap & $\frac{D-D_{L}}{D} \times 100$ & $\begin{array}{l}0,17,33,50,67 \text {, and } 83(\%) \\
\text { respectively }\end{array}$ \\
\hline $\begin{array}{l}\text { Transverse overlap distance or } \\
\text { distance betw een two laser tracks }\end{array}$ & $\mathrm{D}_{\mathrm{T}}$ & $\begin{array}{l}0.6,0.5,0.4,0.3,0.2,0.1(\mathrm{~mm}) \\
\text { respectively }\end{array}$ \\
\hline Transverse overlap & $\frac{\mathrm{D}-\mathrm{D}_{\mathrm{T}}}{\mathrm{D}} \times 100$ & $\begin{array}{l}0,17,33,50,67 \text {, and } 83 \\
\text { (\%)respectively }\end{array}$ \\
\hline $\begin{array}{l}\text { A verage laser energy density per } \\
\text { pulse }\end{array}$ & $E_{d}=\frac{E_{p}}{\left(\frac{\pi}{4} D^{2}\right)}$ & $3.5 \times 10^{6}\left(\mathrm{~J} / \mathrm{m}^{2}\right)$ \\
\hline Effective laser energy density & $E_{\text {eff }}=\frac{E_{p}}{\left(\frac{\pi}{4} D^{2}\right)} \times f$ & $\begin{array}{l}6.02 \times 10^{7}, 7.08 \times 10^{7}, 8.85 \times 10^{7} \\
12.0 \times 10^{7}, 17.7 \times 10^{7}, 35.4 \times 10^{7} \\
\left(\mathrm{~J} / \mathrm{m}^{2}\right) \text { respectively }\end{array}$ \\
\hline Time gap between two pulses & $\operatorname{tg}=1 / f$ & $0.06,0.05,0.04,0.03,0.02,0.01(\mathrm{~s})$ \\
\hline
\end{tabular}


Table 3 Experimentally measured attributes of machined cavities during PM 3D laser machining

\begin{tabular}{cccccc}
\hline $\begin{array}{c}\text { Lateral- } \\
\text { Transverse } \\
\text { overlap } \\
\text { distances, } \\
\mathbf{D}_{\mathbf{L}}-\mathbf{D}_{\mathbf{T}}\end{array}$ & $\begin{array}{c}\text { Lateral- } \\
\text { Transverse } \\
\text { overlap, } \\
\mathbf{O}_{\mathbf{L}}-\mathbf{O}_{\mathbf{T}}\end{array}$ & $\begin{array}{c}\text { Effective } \\
\text { laser energy } \\
\text { density per } \\
\text { second, } \mathbf{E}_{\text {eff }}\end{array}$ & $\begin{array}{c}\text { Sp/Sv } \\
\text { ratio }\end{array}$ & $\begin{array}{c}\text { Average } \\
\text { depth of } \\
\text { cavity } \\
\text { created }\end{array}$ & $\begin{array}{c}\text { Material } \\
\text { removal rate }\end{array}$ \\
\hline$(\mathrm{mm})$ & $(\%)$ & $\left(\mathrm{J} / \mathrm{m}^{2}\right)$ & & $(\mu \mathrm{m})$ & $\left(\mathrm{mm}^{3} / \mathrm{min}\right)$ \\
\hline $0.6-0.6$ & $0-0$ & $6.02 \times 10^{7}$ & 0.33 & $37.1 \pm 2.82$ & $13.36 \pm 0.94$ \\
$0.5-0.5$ & $17-17$ & $7.08 \times 10^{7}$ & 0.63 & $124 \pm 4.68$ & $37.20 \pm 1.56$ \\
$0.4-0.4$ & $33-33$ & $8.85 \times 10^{7}$ & 0.81 & $126 \pm 2.37$ & $30.24 \pm 0.79$ \\
$0.3-0.3$ & $50-50$ & $12.0 \times 10^{7}$ & 1.15 & $167 \pm 4.71$ & $30.06 \pm 1.57$ \\
$0.2-0.2$ & $67-67$ & $17.7 \times 10^{7}$ & 0.89 & $191 \pm 5.39$ & $22.92 \pm 1.80$ \\
$0.1-0.1$ & $83-83$ & $35.4 \times 10^{7}$ & 0.71 & $1000 \pm 8.11$ & $60.00 \pm 2.70$ \\
\hline
\end{tabular}


Table 4 Computationally predicted and experimentally measured surface roughness for PM 3D laser machining conditions

\begin{tabular}{cccc}
\hline $\begin{array}{c}\text { Effective laser energy } \\
\text { density per second, } \\
\mathbf{E}_{\text {eff }}\end{array}$ & $\begin{array}{c}\text { Measured } \mathbf{S}_{\mathbf{z}} \pm \\
\text { standard deviation }\end{array}$ & $\begin{array}{c}\text { Predicted } \\
\mathbf{S}_{\mathbf{z}}\end{array}$ & Difference \\
\hline$\left(\mathrm{J} / \mathrm{m}^{2}\right)$ & $(\mu \mathrm{m})$ & $(\mu \mathrm{m})$ & $(\%)$ \\
\hline $6.02 \times 10^{7}$ & $113.4 \pm 3.67$ & 116.10 & -2.33 \\
$7.08 \times 10^{7}$ & $127.5 \pm 1.96$ & 121.30 & 5.11 \\
$8.85 \times 10^{7}$ & $122.4 \pm 2.11$ & 117.17 & 4.46 \\
$12.0 \times 10^{7}$ & $82.1 \pm 2.02$ & 78.20 & 4.99 \\
$17.7 \times 10^{7}$ & $39.9 \pm 2.29$ & 41.98 & -4.95 \\
$35.4 \times 10^{7}$ & $273.1 \pm 2.56$ & 257.05 & 6.24 \\
\hline
\end{tabular}

